\title{
Worker's Resilience: The Exigency for Empathic Leadership
}

\author{
Regina, Ekiyor \\ Department of Business Administration and Management, \\ Ken Saro-wiwa Polytechnic, Rivers State, Nigeria
}

\begin{abstract}
Research on workers resilience is yet in its formative years. As a growing and developing framework, it offers a strong position on the need for workers optimism, composure and positive outlook on events even during tough or challenging times. This is as theories identify the quality of relationship between leaders and their workers as key to the success and wellbeing of the organization. This paper addressed the role of empathic leadership in the achievement of workers resilience. The paper is designed as a review with content bothering on the conceptualization and link between the empathic leadership and workers resilience. The review espouses the role of empathic leadership in the enhancement of resilience qualities such as optimism, equanimity and humour; it was concluded that empathic leadership drives and has a positive impact on the workers ability to cope with tough times and to maintain composure, optimism and equanimity during such times
\end{abstract}

Keywords: Empathic leadership, workers resilience, optimism, equanimity, emotions

DOI: $10.7176 / \mathrm{EJBM} / 11-17-11$

Publication date:June $30^{\text {th }} 2019$

\section{Introduction}

The growing competition within the business environment as a result of the changes in demography and the social and technological dynamics of globalization are such that place significant pressure on workers, especially those within private firms (Collins, 2007). This is as the worker is considered a core resource and one upon which other activities and operations of the organization depends on. In this vein, it is therefore evident that there is a growing need for workers who are focused, determined and able to maintain composure and purpose despite the challenges and seeming opposition they may encounter in the course of carrying out their roles (Wagnild \& Young, 1993). Nonetheless, it is by this also imperative to understand the necessitating conditions and relationships which can contribute and provide the necessary forms of motivation and drive for workers to achieve resilience in todays highly competitive and exerting workplace.

Workers resilience, according to Drisko (2014) is that state of optimism and equanimity expressed by workers in their functions. It is both a cognitive, emotional and behavioural factor as it extends beyond the perception of events to the interpretations of the events and the actions or attitudes expressed with regards to the experience of the event. Collins (2007) noted that the success of organizations is tied to the focus and commitment of their workers, this is as Steer (1994) agreed that while commitment plays a critical in the quality of services and output, it is however resilience that sustains the workers drive and determines his or her willingness to continue in the face of discomfort and distress.

Studies (Fredrickson \& Cohn, 2008; Fredrickson, 1998) on workers resilience suggest that most often, interpretations of events are premised on their relationships and the features of their exchange within the organization. A dominant position on this is that leadership, especially that which is empathetic and concerned has a way of stimulating trust and confidence in their worker to surmount change and discomfort. Fredrickson (1998) observed that when leaders express interest and concern in workers welfare and wellbeing there is an increased level of identification and believe in the sincerity of the organization, hence increased confidence in self and in the organization.

While research on workers resilience is considered as still evolving, there are however studies that have examined it as an outcome or consequence of several antecedents such as training, compensation, organizational culture (Fisk \& Dionisi, 2010; Drisko, 2014); however, content on the relationship between empathic leadership and workers resilience is relatively scarce. While studies (Stein \& Book, 2000; Shirzad \& Baharak, 2011) have identified emotional intelligence as an overarching factor in leader - employee social exchange and relations, several other studies (Hassan, Saeid, \& Sirous, 2010; Williams, 2001) have identified similar factors which although not as broad a concept as emotional intelligence, yet identify key aspects of emotional exchange between leaders and their followers. Some examples include emotional reflexivity, emotional labour and emotional leadership (Kpakol \& Zeb-Obipi, 2017; Cole, 2000)

The concept of empathic leadership differs and is conceptualized uniquely. This is as it embodies not just the concerns of leadership, but the understanding of situations based on humane interpretations of workers experiences and conditions (George, 2000; Gryn, 2010, Williams, 2001). This study reviews literature on the concepts of empathic leadership, and workers resilience and also attempts to identify the links between the variables. The paper is justified on the basis that it offers content which addresses the observed gap in studies which have addressed 
both variables, and by that can be used to build and improved on existing theoretical models on workers resilience.

\section{Empathy}

Empathy refers to the understanding of the feelings and predicament of others. It is the expression of concern based on interpretations of perception which are founded on actual interaction and connection with significant others (Alston \& Sosa-Fey, 2010). Empathy extends beyond just knowing or being aware of the conditions of others to the undertaking of actions or behaviour inclined towards healthily supporting and accommodating them. Healthily because helping actions should not jeopardize the position (financial and non-financial) of the organization and at the same time should not undermine the choice and position of the helper.

Anderson (2002) noted that the issue of empathy within the organization is one which is highly relative. He notes that while the priority of the organization and the reason for its existence is its goals and the purpose of profit, nonetheless, its utility and engagement of human resources calls for a humane and often times, considerate approach in its dealings with workers. This in no way deviates or distracts the organization from its initial goal of profitability, but rather enhances its competitiveness and commitment levels due to the sense of trust and confidence developed in the key parties involved: leadership and the workers (George et al, 2007).

Empathy denotes the position of connecting and encouraging others from a position of understanding, not tolerance (Bizhan et al, 2012). The key distinguishing feature between understanding and tolerance is that while the former acknowledges situations and is willing to support and encourage, the latter, barely makes room for the situation out of consideration and a sense of obligation. Empathy as noted requires an understanding (cognitive) of the situation, an expression of concern and connection (emotional) and the engagement in actions that of value and intended to support, assist or encourage (behavioural) (Dasborough \& Ashkanasy, 2002). In this manner, it does not tolerate, but supports based on understanding. Within the workplace, it is imperative for collaboration and a sense of placement or belonging given its bonding effect between members or co-workers within the same organization.

\section{Empathic Leadership}

The definition of leadership follows a varied view and highly relative perception of the concept. Yet, there appears to be some consensus in literature as to what make up its key facets and attributes. These are the fact that leadership is based on followership, a sense of purpose and the required tenacity to maintain focus and direction (George, 2000; Gryn, 2010; Williams, 2001). In this way, leadership can also be described as the garnering followership towards the achievement of specific goals or objectives through its ability to sell its ideas and engage in meaningful relationships. Leadership is therefore a process and a continuous one as it is constantly interacting, directing and channelling the organization's resources towards its desired end and goal.

Empathic leadership relates to that form of leadership that utilizes positive emotions in its interactions and behaviour within the workplace. Empathic leadership is transformational and as such places emphasis on the wellbeing and conditions of its followers (Williams, 2001). Empathic leadership facilitates bonding between leaders and their followers and offers workers a much required reassurance of their relevance and position within the organization. Oyewumi et al (2015) observed that leadership that is void of emotions and which has no considerations for the plight of workers is often endured and has a lose hold on the loyalty of commitment of its followers. On the other hand, leadership which is empathic and which acts in ways or patterns that suggest care, consideration and support for workers, is often endearing and with the capacity to effectively engage and stimulate commitment and loyalty from its workforce.

In their study Hassan et al (2010) described leaders with emotional skills as a priority in todays business world. In their opinion, leadership should identify with the changes in global industries, economies and should recognize the imperatives for a more motivated and loyal workforce. Building on their position, Oyewumi et al (2015) added that the recognition and value for the worker is a fundamental premise for building stronger and healthier relationships within the workplace. Empathic leadership according to Stein and Book (2000) from this angle recognizes the differences in workers, the nature of diversity, backgrounds, experiences and is therefore willing to engage the worker at that level and to motivate and bring out the best in them. Strait-jacketing the worker to conform through strict policies which are uncompromising and which are inconsiderate of the existing differences or diversity within workers does not suggest or indicate adaptability of a position in line with the changing business times.

The position of previous studies (Johnson, 2008; Borman \& Motowildo, 1997) follows that through empathy leaders are also able to effectively sell their ideas, ideologies and engage their workers in the pursuit of organizational goals. Furthermore, leadership should also follow a more people-oriented approach which recognizes the value and contributions of its staff in its processes, objectives and goals. This is as George (2000) opined that the evidence of the growing gap between organization treatment of their staff and the expectations they hold of them is unrealistic and fallible (Stein \& Book, 2000; Williams, 2001). To get the best and to retain the best, organizations ought to focus on policies and work conditions that resonate with people-focus and concern. 
Empathy should also be recognized as a major factor in the exchange relationship between leaders and their followers and in that way, organizations can boast of having much more to offer in terms of quality relationships, and supportive groups or workplaces.

\section{Workers Resilience}

Workers resilience details those features and attributes characterized as enabling the worker cope with hard times, uncertainties and pressure from work. Fredrickson (1998) describes workers resilience as a state and not an act, implying the conditioning of resilience must come from within the worker and not a pretentious show of confidence or courage. In his opinion, when such feelings are grounded in the workers psychological and emotional self, they tend to support consistency and an undeterred believe in oneself and in their capacities to scale through any challenge (Cole, 2000). Workers resilience therefore describes the workers positive interpretations conditioning and behaviour with regards to happenings and their experiences of events within their work environment.

Adamson et al (2014) affirm that when workers are resilient, there is a higher tendency for the organization to reach its goals. Collins (2007) noted that resilience in workers is expressed in their level of optimism, equanimity and in their approach towards tasks. In his opinion, workers who are resilient tend to be positive about events and even in the face of challenges and difficulties, never seem to lose their sense of humour. Similarly, Wagnild and Young (1993) observed that while much of previous research has dwelled on resilience at the organizational level, a great deal of the robustness and adaptive capacity of the organization is drawn from the functions and consistency of its staff in their role performance. In this manner, it is evident that the resilience of the worker brings a lot more to the table in terms of workers attitude towards their roles, their relationships with co-workers and the quality of their output.

Some of the advantages which Adamson et al (2014) opined can be linked to a resilient workforce are (a) the reassurance circulated within the workplace, and thus an environment of confidence and focus, (b) an optimistic workforce with positive outlooks on the turn out of events, (c) it enhances the health and wellbeing of the organization based on the richness of the relationships, and (d) it enhances workers confidence in their own capabilities and as such as a positive effect on the overall performance of the organization. These are some of the factors which accrue from having resilient workers; in general workers resilience is considered a major factor in the competitiveness of the organization and a as a significant indicator of the quality of relationship within the workplace.

\section{Empathic Leadership and Workers Resilience}

Dasborough and Ashkanasy (2002) noted that within the workplace, workers tend to mirror the emotions of their leader. In his view, when the leader is enthusiastic or happy, the subordinates tend to resonate with a similar mood. In another vein, Johnson (2008) opined that leadership which is empathic has a strong effect on workers behaviour as it is reassuring and helps to build workers confidence in themselves and in their abilities to surmount any challenge or obstacle. This suggests that through their expression of concern and understanding, empathic leaders are able to connect better with their followers. Their level of correspondence is deeper, and with more significant outcomes in terms of motivation and morale.

Several studies (Hassan et al, 2010; George et al, 2007; Alston \& Sosa-Fey, 2010) affirm to the usefulness of empathy in the workplace and in generating the required levels of confidence and optimism in workers during tough or difficult times. This is as the strength of the relationship between the key parties (employers and employees) is defined by the extent to which both parties trust and identify with each other (Gryn, 2010; Johnson, 2008). Likewise, the poor attention and poor application of empathy in working relationships tends to stifle communication and to mechanize it, thus making it void of emotions, concern or empathy. The conditions which drive and enhance workers resilience are such that develop their own trust and confidence in their abilities, shifts their perceptions of events or circumstances from negative to positive, and strengthens their resolve in the performance of their roles and in the accomplishments of tasks.

\section{Conclusion}

Workers resilience is critical and imperative for the success and wellbeing of the organization. Its evidence within the workplace promotes an overall sense of confidence in the organizations capabilities to surmount and effectively attend to various forms of pressure, change incidents and environmental challenges. The review espouses the role of empathic leadership in the enhancement of resilience qualities such as optimism, equanimity and humour; this is as the extant literature identifies empathic leadership as being effective in stimulating confidence, trust and as providing reassurance to workers with regards to their roles. These in turn stimulate and drive the resilience of workers. As such, it is the position of this study that empathic leadership drives and has a positive impact on the workers ability to cope with tough times and to maintain composure, optimism and equanimity during such times. 


\section{References}

Adamson, C., Beddoe, L. \& Davys. A. (2014). "Building Resilient Practitioners: Definitions and Practitioner Understandings." British Journal of Social Work, 44(3), pp.522-541.

Alston, B.A., \& Sosa-Fey, J. (2010). Emotional intelligence and leadership: A study of human resource managers. International Journal of Business and Public Administration, 7(2), 61-75.

Anderson, T. (2002). Modes of interaction in distance education: Recent developments and research questions. In M. Moore (Ed.) Handbook of Distance Education. (p. 129-144). Mahwah, NJ.: Erlbaum.

Bizhan, S., Saeid B. \& Vahid, B. (2012). The Relationship between Leadership Style and Employee Performance singaporean journal of business economics, and management studies. 2, 5.

Borman, W., \& Motowildo, S. (1997). Task performance and contextual performance: The meaning for personnel selection research. Human Performance, 10, 2, 99-109.

Cole, G.A. (2000). Management theory and practice London. Ashford Colour Press

Collins, S. (2007). "Social Workers, Resilience, Positive Emotions and Optimism." Practice, 19 (4), pp. $255-269$.

Dasborough, M. T; \& Ashkanasy, N. M. (2002). 'Emotion and attribution of intentionality in leader-member relationships'. The Leadership Quarterly,13, pp. 615-634.

Drisko, J. (2014) 'Competencies and Their Assessment', Journal Of Social Work Education, 50 (3), pp. 414-426.

Fisk, G. \& Dionisi, A. (2010). "Building and Sustaining Resilience in Organizational Settings: The Critical Role of Emotion Regulation." In Emotions and Organizational Dynamism (Research on Emotion in Organizations, Vol. 6), edited by Ashkanasy, N.M., Zerbe, J.W. \& Hartel, C.E.J. pp. 167-188. Bingley: Emerald.

Fredrickson, B. L. (1998) What good are positive emotions? Review of General Psychology, 2, 300-319.

Fredrickson, B. L., \& Cohn, M. A. (2008). Positive emotions. In M. Lewis, J. Haviland, \& L. F. Barrett (Eds.), Handbook of emotions (3rd ed.). New York, NY: Guilford Press.

George, B., Sims, P., McLean, A. N., \& Mayer, D. (2007). Discovering your authentic leadership. Harvard Business Review, 8, 2, 129-138

George, J.M. (2000). Emotions and leadership: The role of emotional intelligence. Human Relations, 53(8), $1027-$ 1055

Gryn, M. (2010). The Relationship Between the Emotional Intelligence and Job Performance of Call Centre Leaders. MSc Thesis, University of South Africa.

Hassan, J., Saeid, J., \& Sirous, K. (2010). Impact of Emotional Intelligence on Performance of Employees Postmodern Openings, 1, Vol 4, pp: 63-74

Johnson, S.K. (2008). I second that emotion: Effects of emotional contagion and affect on leader and follower outcomes. Leadership. Q. 2008, 19, 1-19.

Oyewumi, O.A., Ojo, S.I., Oludayo, A.O. (2015). Leaders' emotional intelligence and employees' performance: A case in Nigeria's public healthcare sector. International Journal of Human Resource Studies. 5(3).

Shirzad, K., \& Baharak, Z. F. (2011). The relationship between senior managers' leadership style of school districts of Tehran and spirit of the administrators in girls' state school. Journal of Management Research and Training.

Steer, R. M. (1994). Work and stress, introduction to organizational. New York, NY: Addison-Wesley

Stein, S. J. \& Book, H. E. (2000). The EQ Edge: Emotional intelligence and your success. Canada: Multi-Health Systems

Wagnild, G., \& Young, H. (1993). Development and psychometric evaluation of the resilience scale. Journal of Nursing Measurement, 1(2), 165-178.

Williams, S. (2001). Emotion and Social Theory, London: Sage. 